Gut, 1980, 21, 137-140

\title{
Relationship of proctitis and rectal capacity in Crohn's disease
}

\author{
P BUCHMANN,* G A G MOGG, J ALEXANDER-WilliaMS, R N ALLAN, AND \\ M R B KEIGHLEY
}

From the General Hospital, Birmingham

SUMmARY In patients with Crohn's disease involving the rectum $(n=25)$, there was an inverse relationship between rectal capacity and the degree of proctitis. However, in patients with Crohn's disease not involving the rectum $(n=22)$ the rectal capacity was similar to that of normal controls $(n=20)$. The frequency of defaecation was not related to the degree of proctitis or to the pressure of a colectomy and ileorectal anastomosis. Control subjects had a significantly lower frequency of defaecation than patients with Crohn's disease irrespective of involvement of the rectum.

The effect of rectal distension on defaecation has been studied in patients with rectal prolapse and megacolon. ${ }^{12}$ The extent to which a subject tolerates rectal distention depends on his or her individual sensitivity. This tolerance tends to decrease in elderly patients and is reduced in an inflamed rectum..$^{34}$ The present study evaluates the relationship between rectal capacity and the presence or severity of proctitis in Crohn's disease.

\section{Methods}

\section{PATIENTS}

Forty-seven patients with histologically proven Crohn's disease were studied. There were 25 females (mean age 38 years, 17-65) and 22 males (mean age 34.4 years, 19-59). There were two groups, 24 patients had undergone total colectomy and ileorectal anastomosis and the remaining 23 had had caecal excision with resection of the terminal ileum. There were four patients with a diverting ileostomy in each group.

Twenty subjects, nine females (mean age 41 years, 25-96 years) and 11 males (mean age 49 years, 26-75 years) with no gastrointestinal symptoms acted as controls.

\section{METHOD}

Patients were asked about frequency of defaecation and consistency of the stool. Sigmoidoscopy was performed to at least $20 \mathrm{~cm}$ with a rigid instrument without bowel preparation. The sigmoidoscopic findings were graded by an arbitrary score as

*Address for reprint requests: Peter Buchmann, Surgical Clinic A, University Hospital, 8091 Zurich, Switzerland.

Received for publication 13 August 1979 shown in the Table. Rectal capacity was measured with a Latex balloon, measuring $50 \times 120 \mathrm{~mm}$ attached over a polyethylene tube (external diameter $4 \mathrm{~mm}$ ). The tube was placed in the rectal ampulla, so that the lower end lay $2-3 \mathrm{~cm}$ above the dentate line. In the control subjects and those with mild proctitis the balloon was inflated incrementally with $50 \mathrm{ml}$ aliquots of air injected over 10 seconds allowing a 30 second rest between each insufflation. In patients with moderate or severe proctitis only $10 \mathrm{ml}$ of air was injected each time. Inflation was stopped when rectal distension became intolerable or reached a volume of $400 \mathrm{ml}$. The patient was asked to indicate (1) when a sense of rectal distention was first appreciated (sensation threshold); (2) when the sensation of rectal distention persisted during the 30 second rest (constant sensation); and (3) when the sensation became intolerable (maximal tolerated volume).

\section{Table Assessment of proctitis}

\begin{tabular}{lc}
\hline & Number of points \\
\hline Rectal appearance & \\
Absence of vessels & 1 \\
Fine granularity of mucosa & 2 \\
Coarse granularity of mucosa & 3 \\
Contact bleeding & 3 \\
Ulceration & 1 \\
Seen at only one site & 2 \\
Present throughout rectum & 3 \\
Large confluent ulcers & \\
Extent of any visible abnormality & 1 \\
Below 8 cm & 2 \\
Entire rectum & 5 core \\
Grade of proctitis & 0 \\
Normal & $1-3$ \\
Slight & $4-7$ \\
Moderate & $8-11$ \\
Severe & \\
\hline
\end{tabular}


Radiological evaluation of rectal capacity was not studied in symptomatic patients. It was considered to be unethical in control subjects and patients with no clinical indication for its use.

\section{Results}

The patients were grouped according to the degree of proctitis which was assessed as shown in the Table.

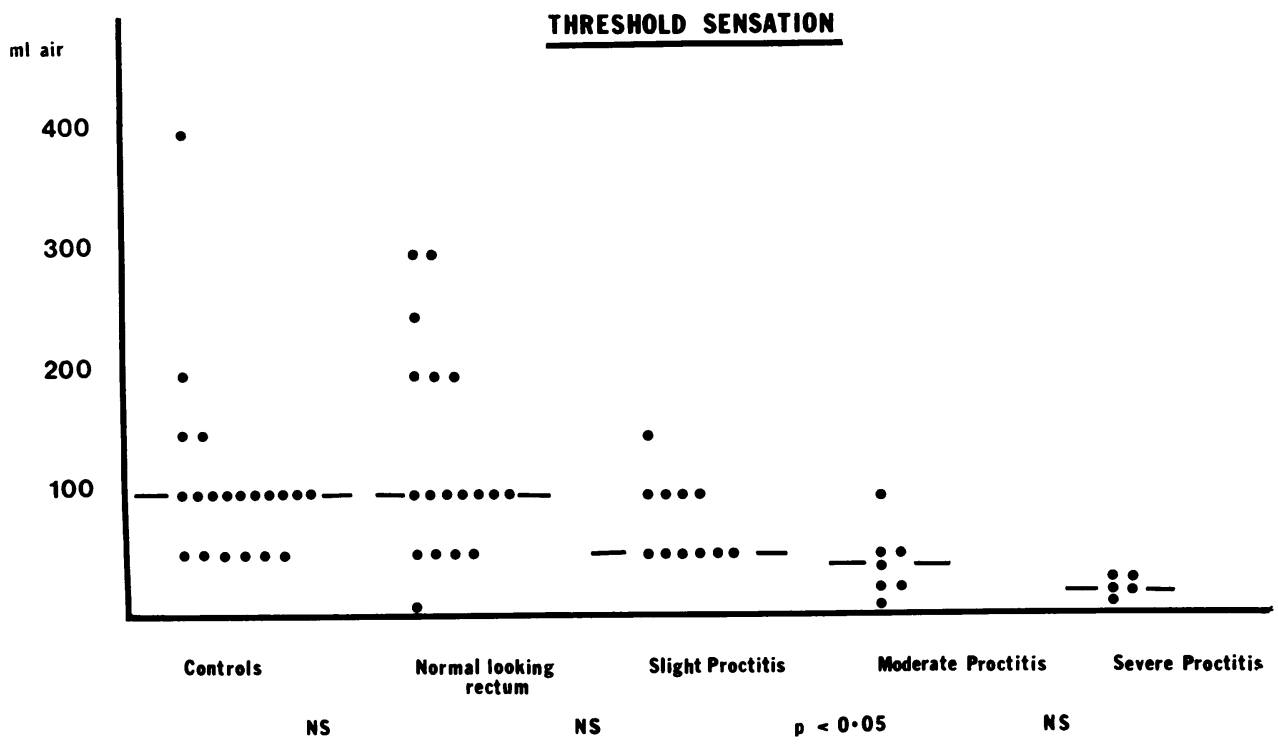

Fig. 1 Volume of rectal filling in millilitres of air to achieve threshold sensation in control subjects and patients with Crohn's disease.

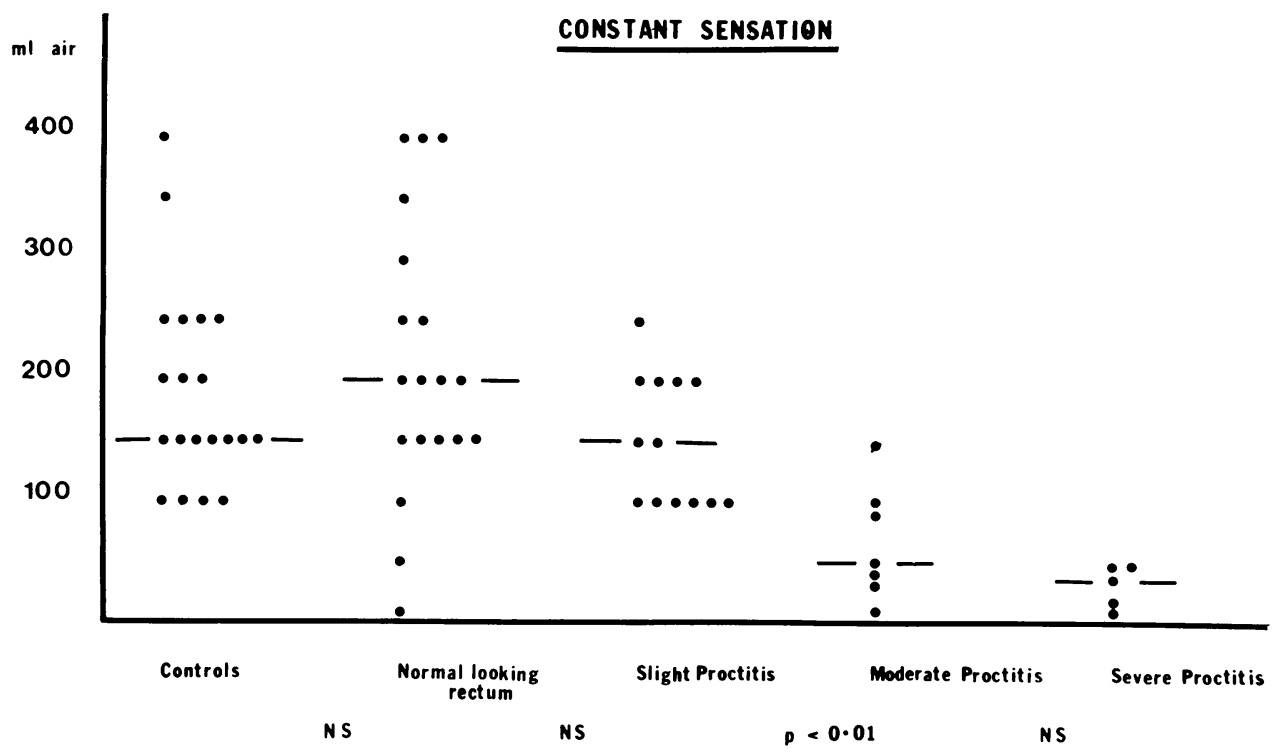

Fig. 2 Volume of rectal filling in millilitres of air to achieve constant sensation in control subjects and patients with Crohn's disease. 


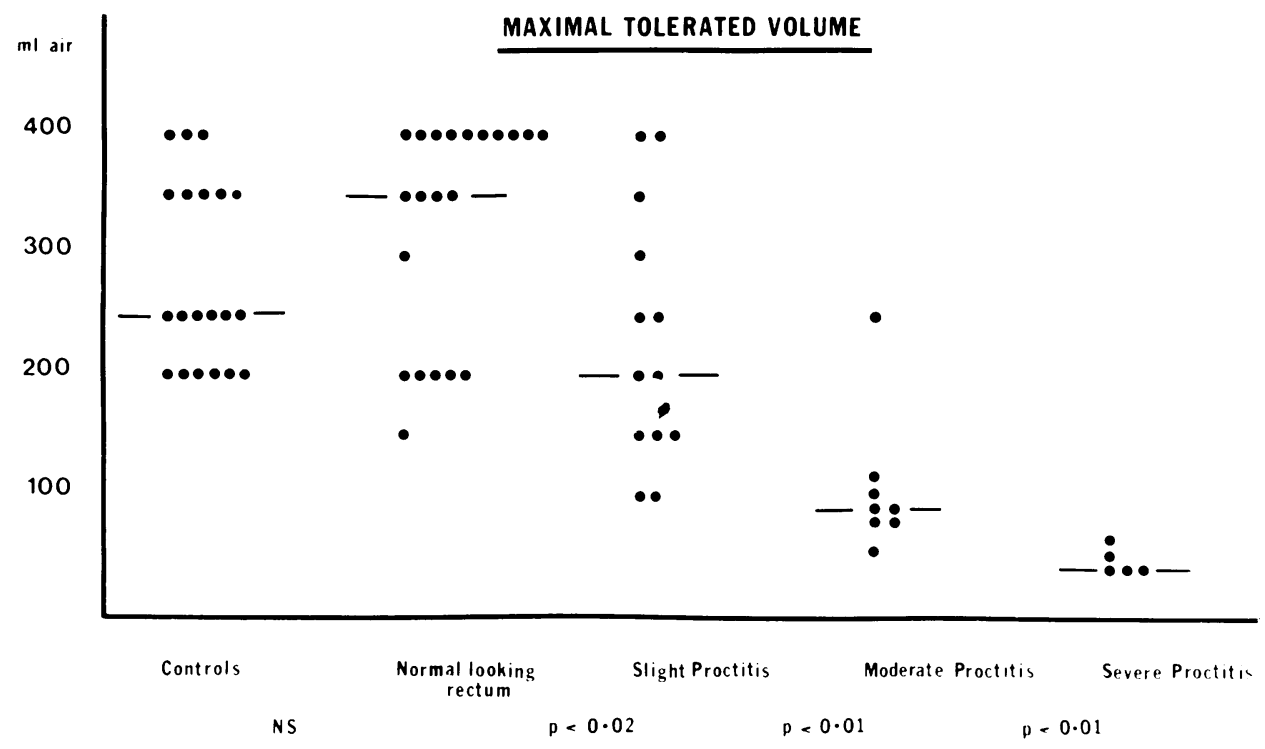

Fig. 3 Volume of rectal filling in millilitres of air to achieve maximal tolerated volume in control subjects and patients with Crohn's disease (statistical evaluation with the Wilcoxon rank test).

There were 22 patients with no evidence of rectal involvement, 13 with mild proctitis, seven with moderate proctitis, and five with severe proctitis. There was an inverse relationship between rectal capacity and the degree of proctitis. At the sensation threshold (Fig. 1) and constant sensation (Fig. 2) there was a statistically significant difference in rectal capacity in those patients with moderate proctitis as compared with the other groups. At the maximal tolerated volume (Fig. 3) a significant difference was achieved at all grades of proctitis compared with those Crohn's patients without proctitis. The maximal tolerated volume was unaffected by the presence of a colectomy and ileorectal anastomosis. In Crohn's patients without proctitis the results were similar to the controls. However, only three of the 20 controls tolerated a distention of $400 \mathrm{ml}$ of air before experiencing discomfort, whereas 10 of 22 patients in the Crohn's disease group without rectal inflammation were able to tolerate inflation of the balloon up to $400 \mathrm{ml}$ and most could have tolerated more.

Nine patients experienced occasional incontinence, which was always associated with urgency. Soiling occurred only as a result of extreme urgency. No significant difference in stool frequency was observed in Crohn's patients with or without proctitis. However, there was a significantly higher frequency of defaecation in Crohn's disease patients without proctitis (median three stools/day, range one to seven) than in controls (median one stool/day, range one to two $)(P<0.02)$. Patients with or without a colectomy and ileorectal anastomosis had a similar stool frequency.

There was no significant difference in the maximal tolerated volume between controls and patients with slight proctitis, but a highly significant difference between controls and patients with moderate proctitis $(\mathrm{P}<0.01)$.

\section{Discussion}

Evaluation of proctitis by sigmoidoscopy findings is influenced by observer error, ${ }^{5}$ although the most important abnormal features are well defined. In an attempt to achieve objectivity all endoscopies were made by one observer (PB).

Assessments of different techniques to measure rectal capacity have shown that an air-filled balloon provides the most reproducible results. ${ }^{3}$ However, the differences between the volumes recorded in our study and others might be due to the different dimensions of the balloon we used.

The relationship between the degree of proctitis as observed sigmoidoscopically and rectal capacity is statistically significant. A similar relationship was found in patients with ulcerative colitis. ${ }^{4}$ As Crohn's disease involves the whole thickness of the bowel wall, the decrease in maximal tolerated volume with increased proctitis might be caused by either an increased sensitivity of the nerve plexus or an increase in the rigidity of the rectal wall. We suggest 
that both factors may be responsible. First the sensation threshold was apparent immediately after introducing the balloon into the rectum in Crohn's disease patients, but never in control subjects. Secondly, the reduced distensibility of a rectum with severe proctitis can be appreciated by the observer on sigmoidoscopy.

Although, in normal subjects, the rectal walls are usually opposed, ${ }^{6}$ normal or even increased distensibility of the rectum with mild proctitis may help those patients with an ileorectal anastomosis to have a tolerably low frequency of defaecation.

It is interesting to notice that frequency of defaecation was not related to the degree of proctitis. Patients with regional enteritis often have stools with a consistency like porridge which they pass more frequently. Nevertheless, soft stools or the presence of proctitis was not found to be the cause of occasional incontinence. In this group, incontinence was related to urgency, which, in its turn, was related to the speed of filling of the rectum.?

It is known from studies in other conditions that the sensitivity of the rectal wall to distention is increased in disease states. ${ }^{8-10}$ Although there is no significant difference between maximal tolerated volume in patients with Crohn's disease without proctitis and controls, the proportion of patients tolerating $400 \mathrm{ml}$ of air in the rectal balloon without any discomfort was higher in the patients with regional enteritis. It is possible that Crohn's disease damages the muscle or nerves of the bowel and decreases its sensitivity before it has any demonstable effect on the mucosa. ${ }^{11} 12$

PB was supported by a fellowship of the Swiss National Science Research Foundation.

\section{References}

${ }^{1}$ Porter NH. A physiological study of the pelvic floor in rectal prolapse. Ann R Coll Surg Engl 1962; 31:379-404.

${ }^{2}$ Tobon F, Reid NCRW, Talbert JL, Schuster MM. A manometric test for the diagnosis of Hirschsprung's disease (Abstract). Gastroenterology 1967;52:1143.

${ }^{3}$ Ihre T. Studies on anal function in continent and incontinent patients. Scand J Gastroenterol (Suppl) 25 $1974 ; 9$.

${ }^{4}$ Farthing MJG, Lennard-Jones JE. Sensibility of the lectum to distension and the anorectal distension reflex in ulcerative colitis. Gut 1978;19:64-69.

${ }^{5}$ Baron JH, Connell AM, Lennard-Jones JE. Variation between observers in describing mucosal appearances in proctocolitis. Br Med J 1964;1:89-92.

${ }^{6}$ Schuster MM. The riddle of the sphincters. Gastroenterology 1975;69:249-262.

'Buchmann P, Keighley MRB, Allan RN, AlexanderWilliams J. Pathogenesis of urgency in inflammatory bowel disease. 1979 (unpublished observations).

${ }^{8}$ Todd IP. Etiological factors in the production of complete rectal prolapse. Postgrad Med J 1959;35:97-100.

${ }^{9}$ Todd IP, Nixon HH, Connell AM, et al. Discussion on megacolon and megarectum with emphasis on conditions other than Hirschsprung's disease. Proc $R$ Soc Med 1961 ;54:1035-1056.

${ }^{10}$ Duthie HL. Rectal prolapse. In Irvine WT, ed. Modern Trends in Surgery, London. Butterworth. 1971;3:90108.

${ }^{11}$ Goodman MJ, Skinner JM, Truelove SC. Abnormalities in the apparently normal bowel mucosa in Crohn's disease. Lancet 1976; 1: 275-278.

${ }^{12}$ Dunne WT, Cooke WT, Allan RN. Enzymatic and morphometric evidence for Crohn's disease as a diffuse lesion of the gastrointestinal tract. Gut 1977;18:290-294. 